UDK: 005.334:614.75

DOI: https://doi.org/10.24867/08NU01Zoric

\title{
PROCENA UGROŽENOSTI OD ELEMENTARNIH NEPOGODA I DRUGIH NESREĆA ZA JKP "RADNIK" SIVAC
}

\section{ASSESSMENT OF THE RISK OF NATURAL AND OTHER DISASTERS FOR JKP "RADNIK" SIVAC}

\author{
Drago Zorić, Fakultet tehničkih nauka, Novi Sad
}

\section{Oblast - UPRAVLJANJE RIZIKOM OD KATASTROFALNIH DOGAĐAJA I POŽARA}

Kratak sadržaj -Tema ovog rada je procena rizika za JKP “Radnik" Sivac koja obuhvata objekte i prostor $u$ vlasništvu pravnog lica (lokacija Sivac), koji mogu biti ugroženi elementarnim nepogodama i drugim nesrećama. Usled elementarnih nepogoda i drugih nesreća moguće su negativne posledice po samo preduzeće, širu zajednicu $i$ okolinu. Negativne posledice se pre svega ogledaju kroz ugroženost života i zdravlja ljudi, ugroženost poslovanja, ugroženost životne sredine i društvene stabilnosti.

Ključne reči: katastrofe, rizik, upravljanje rizicima, preventivne mere, procena opasnosti

Abstract - The research topic is a risk assessment of JKP "Radnik" Sivac, where the premises are located (Sivac area), which could be affected by a major natural disaster and other accidents. Due to natural and other disasters they are possible negative consequences for the company, the wider community and the environment. The negative consequences are primarily reflected in the threat to life and human health, the threat to business, the threat to the environment and social stability.

Keywords: disaster, risk, risk management, preventive measure, hazard assessment

\section{UVOD}

Savremeni svet i novo doba doneo je sa sobom visok tehničko-tehnloški napredak, a sa njim i pretnje, opasnosti i ugrožavanje životne sredine i bezbednosti duštva u celini. Tako da, pored prirodnih elementarnih nepogoda, $\mathrm{i}$ ljudi veštačkim putem umnožavaju i povećavaju prirodne pojave sa katastrofalnim posledicama [1].

Zakonom o smanjenju rizika od katastrofa i upravljanju vanrednim situacijama [2] u našoj zemlji uređuje se smanjenje rizika od katastrofa, prevencija i jačanje otpornosti i spremnosti pojedinaca i zajednice za reagovanje na posledice katastrofa, zaštita i spasavanja ljudi, materijalnih, kulturnih i drugih dobara, prava i obaveze građana, udruženja, pravnih lica, organa jedinica lokalne samouprave, autonomnih pokrajina i Republike Srbije, upravljanje vanrednim situacijama, funkcionisanje civilne zaštite, rano upozoravanje, obaveštavanje i uzbunjivanje, međunarod-

\section{NAPOMENA:}

Ovaj rad proistekao je iz master rada čiji mentor je bila dr Mirjana Laban, vanr. prof. na saradnja, inspekcijski nadzor i druga pitanja od značaja za organizovanje i funkcionisanje sistema smanjenja rizika od katastrofa i upravljanja vanrednim situacijamama.

Procena je urađena na osnovu raspoloživih podataka iz "Procene ugroženosti opštine Kula" iz 2011. godine [5], pre svega polazeći od indentifikovane ugroženosti kritične infrastrukture za teritoriju Autonomne Pokrajine Vojvodine za Zapadnobački okrug, opštinu Kula, a koji su primenljivi i u skladu su sa važećom Metodologijom za izradu procene ugroženosti od elementarnih nepogoda i drugih nesreća i planova zaštite i spasavanja u vanrednim situacijama [3].

\section{JKP ,RADNIK“ SIVAC}

Uprava Javnog komunalnog preduzeća „Radnik“ Sivac locirana je u neposrednoj blizini centra naseljenog mesta Sivac, u ulici Maršala Tita br. 186.

Sivac je naseljeno mesto $u$ opštini Kula $u$ Zapadnobačkom okrugu. Površina naseljenog mesta Sivac iznosi $152,7 \mathrm{~km}^{2}$, ima 8029 stanovnika i nalazi se na nadmorskoj visini od $103 \mathrm{~m}$ sa pozicionim koordinatama $45^{\circ} 42^{\prime} 09^{\prime \prime} \mathrm{N}$ i $19^{\circ} 22^{\prime} 54^{\prime} 08^{\prime \prime} \mathrm{E}$ [5].

Osnovna delatnost JKP „Radnik“ Sivac od osnivanja pa do danas je snabdevanje vodom naseljenog mesta Sivac i naselja Mali Stapar.

Procena rizika i implementacija mera za smanjenje rizika u okviru preduzeća JKP „Radnik“ Sivac, omogućene su primenom propisa za smanjenje rizika, kao i primenom drugih propisa koji se primenjuju u cilju otklanjanja opasnosti i nastanka štete na ugroženim štićenim vrednostima u koje spadaju:

- život i zdravlje ljudi,

- ekonomija-ekologija i

- društvena stabilnost.

$\mathrm{Na}$ osnovu rezultata preliminarne analize svih opasnosti i njihovog uticaja [4], izveden je zaključak, da je potrebno da se izvrši procena rizika od sledećih opasnosti:

-Zemljotres;

- Ekstremne vremenske pojave (snežne mećave, nanosi i poledice).

\section{ZEMLJOTRES}

Intenzitet zemljotresa je opisna veličina koja se određuje prema nekoj od seizmičkih skala. Skale se zasnivaju uglavnom na nivou oštećenja zgrada i drugih objekata, promenama koje je zemljotres izazvao u prirodi, efektom na ponašanje ljudi i životinja, izazvanim različitim 
intezitetima potresa. Oštećenja objekata zavise od konstrukcije koje se mogu svrstati u tri osnovne grupe [4]:

- I grupa: Zgrade od neobrađenog kamena, seoske zgrade, zgrade od čerpića i naboja,

- II grupa: Obične zgrade od opeke, zgrade od velikih blokova, zgrade od prefabrikovanih materijala, zgrade od prirodnog tesanog kamena i zgrade sa delimično drvenom konstrukcijom,

- III grupa: Armirano-betonske građevine.

Teritorija naseljenog mesta Sivac se nalazi na trusnoj oblasti Vojvodine. U posmatranom periodu poslednjih 50tak godina na ovom području je registrovano više zemljotresa manjeg inteziteta koji nisu prouzrokovali materijalnu štetu na stambenim i privrednim objektima, infrastrukturi i sistemu snabdevanja energijom[4].

Prema karti seizmičkog hazarda na površini lokalnog tla teritorija naseljenog mesta Sivac je u zoni očekivanih zemljotresa do $6^{\circ} \mathrm{MCS}$ skale, za povratni period od 95 godina[6]. Zato je u Generalnom planu opštine Kula propisano da se konstrukcije obezbeđuju na $7^{\circ} \mathrm{MKS}$. Za većinu objekata, koji se svrstavaju u II i III kategoriju (stambeni objekti pomoćno-proizvodne zgrade) [5].

\section{PROCENA UGROŽENOSTI OD ZEMLJOTRESA ZA JKP ,RADNIK“ SIVAC}

Zemljotres predstavlja neželjeni događaj koji zavisno od epicentra zahvata veći deo površine, te usled toga nije moguće tačno ograničiti njegovo dejstvo samo na deo ili celu teritoriju [4].

Neželjeni događaji u slučaju pojave zemljotresa $u$ naseljenom mestu Sivac, bi bili slučajevi povređenih zaposlenih radnika preduzeća „Radnik“ Sivac, i korisnika usluga i uzrokovana materijalna šteta.

Najnepoželjniji momenat zemljotresa je u zimskom periodu, radnim danom u toku radnog vremena kada su zaposleni najviše angažovani na svojim radnim zadacima. Ako bi zemljotres bio $7^{\circ}$ MCS u trenutku maksimalnog korišćenja svih kapaciteta preduzeća došlo bi do panike među korisnicima i otežanog izlaza iz objekta. Pod pretpostavkom da neki delovi objekta ne bi izdržali zemljotres od $7^{\circ} \mathrm{MCS}$, delovi objekta i infrastruktura u objektu bila bi delimično urušena i oštećena. U tom slučaju moglo bi doći do lakših i težih povreda radnika i korisnika usluga, eventualno i smrtnog slučaja, što bi dodatno pogoršalo opšte stanje nastalo usled elementarne nepogode.

\subsection{Najverovatniji neželjeni dogadjaj}

Najverovatniji uzroci povređivanja zaposlenih i korisnika usluga u objektima preduzeća bi bila panika kod zaposlenih i korisnika, propusna moć izlaza iz objekta i mogućnost nastanka požara.

Samo preduzeće JKP „Radnik“ Sivac je u statusu osposobljenog privrednog subjekta za zaštitu i spasavanje na nivou mesne zajednice Sivac i u značajnoj meri bi bile narušene planirane aktivnosti $\mathrm{i}$ operativne mere $\mathrm{u}$ vanrednim situacijama na zaštiti štićenih vrednosti mesne zajednice. Razlog tome je što za zemljotrese na prostoru Republike Srbije ne postoji mogućnost precizne rane najave.
Analizom je utvrđeno da je za Opštinu Kula i naseljeno mesto Sivac rizik od zemljotresa nizak, a kao takav je i prihvatljiv, karta 1.

U slučaju zemljotresa tretman rizika podrazumeva preduzimanje preventivnih mera pre svega u vezi sa:

- Razradom $u$ internom planu zaštite i spasavanja $u$ vanrednim situacijama;

- Pridržavanjem propisanih urbanističkih mera koje se odnose na zemljotres;

- Upoznavanjem zaposlenih i njihovoj edukaciji u vezi postupaka u slučaju ove elementarne nepogode.

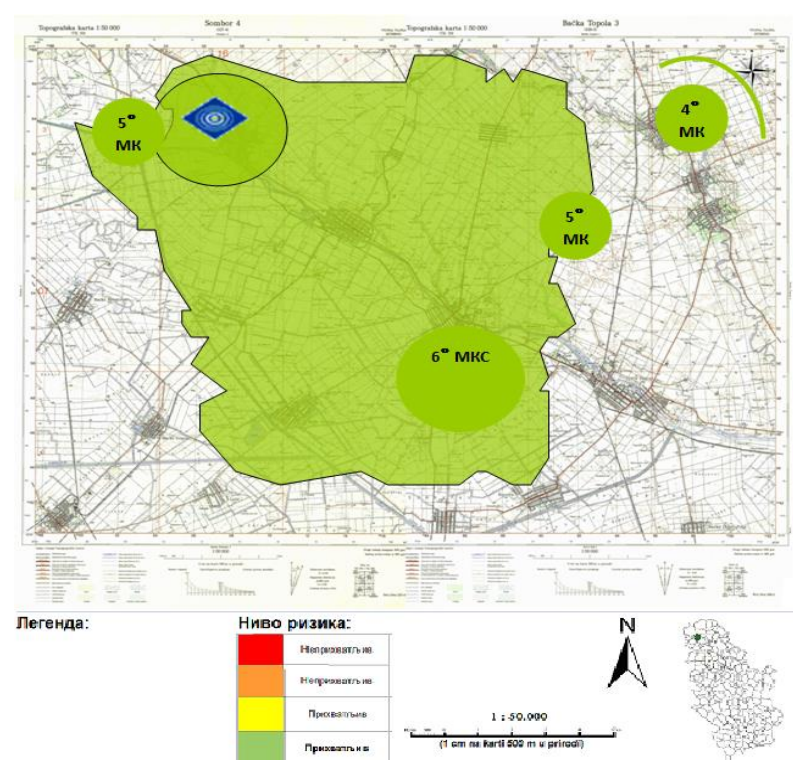

Karta rizika br.1. Scenario zemljotresa Opština Kula, najverovatniji neželjeni događaj [6]

\subsection{Neželjeni događaj sa najtežim mogućim posledicama}

Neželjeni događaj sa najtežim mogućim posledicama je događaj koji se retko pojavljuje na određenom prostoru, a u slučaju njegovog nastanka ima takav intenzitet čije posledice su katastrofalne za sve štićene vrednosti.

Verovatnoća nastanka zemljotresa postoji, očekuju se posledice po štićene vrednosti. Izvor rizika je zemljotres na teritoriji Sivca, karta 2. .

U slučaju zemljotresa događaji koji najviše ugrožavaju štićene vrednosti su povređivanje radnika, velika materijalna šteta na objektima, opremi i robi i infrastrukturnim celinama.

Analizom je utvrđeno da je za JKP „Radnik“ Sivac rizik od zemljotresa umeren, što čini rizik prihvatljivim.

Tretman rizika je u vezi sa:

- Razradom u internom planu zaštite i spasavanja $u$ vanrednim situacijama;

- Pridržavanjem propisanih urbanističkih mera koje se odnose na zemljotres;

- Razvoj internog sistema razglasa;

- Redovnoj obuci zaposlenih za pružanje prve pomoći, ZOP i njihovoj edukaciji u vezi postupaka u slučaju ove elementarne nepogode. 


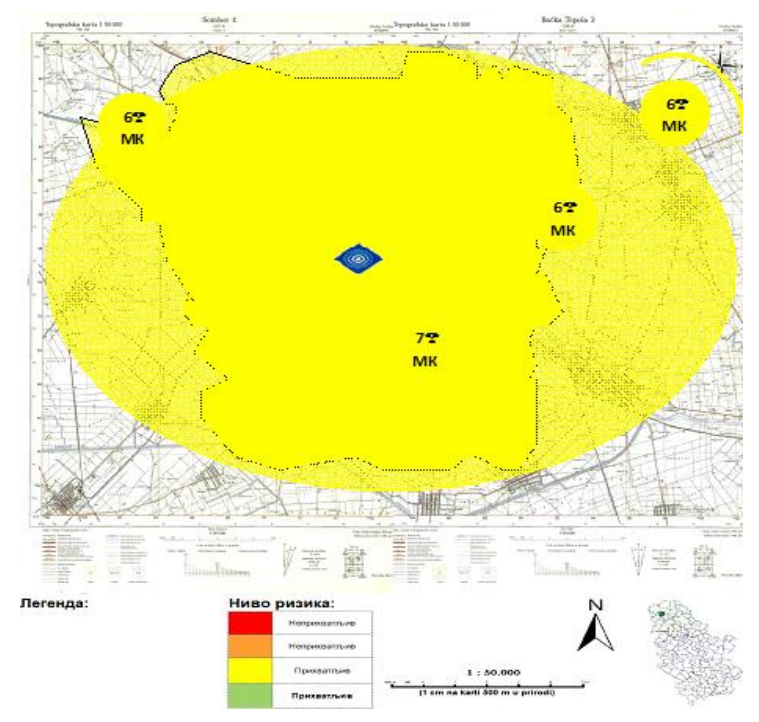

Karta rizika br.2. Scenario zemljotresa, JKP "Radnik" Sivac, zemljotres, scenario neželjeni događaj sa najtežim mogućim posledicama [6].

\section{EKSTREMNE VREMENSKE POJAVE (SNEŽNE MEĆAVE, NANOSI I POLEDICE)}

Zimska sezona u umerenim geografskim širinama karakteriše se niskim temperaturama i snežnim padavinama. Pored ovoga, moguće su pojave poput poledice, mećave $i$ snežnih nanosa. Mećave, snežni nanosi i poledice relativno su česte i uobičajene snežne pojave i kao takve ne predstavljaju elementarnu nepogodu.

Ono što predstavlja ozbiljnu opasnost su produženi hladni talasi koji čine da sve navedene pojave traju duže i budu rasprostranjenije. Poslednji put jedan takav hladan talas pogodio je Srbiju u februaru 2012. godine. Pored uvođenja vanredne situacije na nivou cele države i velikih ekonomskih šteta koje je privreda pretrpela, bile su i 22 ljudske žrtve [4].

\section{PROCENA UGROŽENOSTI OD EKSTREMNIH VREMENSKIH POJAVA (SNEŽNE MEĆAVE, NANOSI I POLEDICA) ZA JKP „RADNIK“ SIVAC}

Period najvećih snežnih padavina na teritoriji naselja Sivac su meseci decembar, januar i februar. $\mathrm{Na}$ osnovu hidrometeoroloških podataka u odbrani od snežnih mećava, nanosa i poledica na saobraćajnicama u naselju Sivac može se konstatovati da elementarna nepogoda ovoga tipa nije do sada obuhvatala celu teritoriju mesta, već samo određene rejone. Snežni nanosi i poledice javljaju se nadelu puta M-3 (Vrbas - Sombor). Snežni nanosi se mogu javiti i na deonici železničke pruge Sombor - Vrbas.

Ugroženost od poledica na saobraćajnicama na teritoriji naselja se najčešće javlja na usponima i krivinama na putevima. Pored redovne zaštite puteva od snežnih nanosa može doći do zavejavanja saobraćajnica, saobraćajnotransportnih sredstava i određenog stepena ugroženosti života i zdravlja putnika koji se zateknu na putevima. Elementarna nepogoda od snežnih nanosa i poledice je posebno izražena pri kombinovanoj pojavi padavina $\mathrm{i}$ vetrova.

\subsection{Najverovatniji neželjeni događaj}

Tokom zimskog perioda 2016. godine, zbog velikih snežnih nanosa koji su dostizali visinu do $3,5 \mathrm{~m}$, kao i olujnog vetra i ledene kiše na čitavoj teritoriji Vojvodine proglašena je vanredna situacija. Svi putni pravci bili su neprohodni za saobraćaj. Blokiran je autoput od Subotice do Novog Sada, kao i magistralni pravci Subotica-Sombor-Vrbas. Svi regionalni prilazi Sivcu bili su neprohodni za saobraćaj.

Uzrok nastanka neželjenih događaja je prodor ekstremo hladnog zimskog talasa sa područja Sibira koje je zahvatilo čitavo područje centralne i istočne Evrope.

Posledice neželjenih događaja po preduzeće „Radnik“ Sivac, bi se ogledale u materijalnoj šteti jer se očekivao i potpuni prekid u izvođenju svih vodoinstalaterskih radova koje uzrokuju ekstremne niske temperature, poledica i snežni nanosi.

Analizom je utvrđeno da je rizik od snežnih mećava, nanosa i poledica za preduzeće „Radnik“ Sivac, prihvatljiv, karta 3 ..

Tretman rizika podrazumeva preduzimanje preventivnih mera u vezi sa:

- Razradom u internom planu zaštite i spasavanja u vanrednim situacijama;

- Formiranjem jedinice CZ opšte namene,

- Praćenje informacija, upozorenja RHMZ i Štaba za VS Kula,

- Redovnoj obuci zaposlenih za pružanje prve pomoći, ZOP i njihovoj edukaciji u vezi postupaka u slučaju ove elementarne nepogode,

- JKP „Radnik“ Sivac će primenom navedenih preventivnih mera omogućiti smanjenje štete $\mathrm{i}$ smanjiti ih iako je nivo rizika po ovom scenariju prihvatljiv.

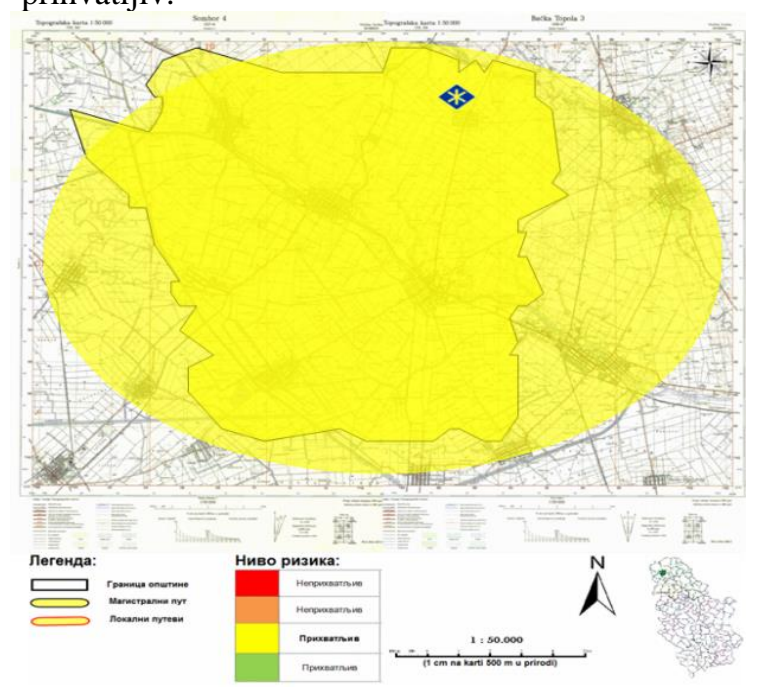

Karta rizika br.3. Snežne mećave, nanosi i poledica JKP"Radnik" Sivac, scenario najverovatniji neželjeni događaj [6]

\subsection{Neželjeni događaj sa najtežim mogućim posledicama}

Neželjeni događaj sa najtežim mogućim posledicama je događaj koji se retko pojavljuje na određenom prostoru, a u slučaju njegovog nastanka ima takav intenzitet čije 
posledice su katastrofalne za sve štićene vrednosti. U slučaju navedenog scenarija očekuju se direktne posledice po štićene vrednosti na celom području opštine Kula kao i na pojedine objekte - postrojenja privrednih društva i JKP „Radnik“ Sivac.

Izvor rizika su ekstremni snežni nanosi dugotrajne izrazito niske temperature i pojava poledice. Događaj koji najviše ugrožava štićene vrednosti je nestanak električne energije i kvarovi u elektro instalacijama, potencijalni požar koji može da izbije usled opterećenja sistema.

Analizom je utvrđeno da je rizik od snežnih mećava, nanosa i poledica za preduzeće „Radnik“ Sivac, neprihvatljiv, karta 4.

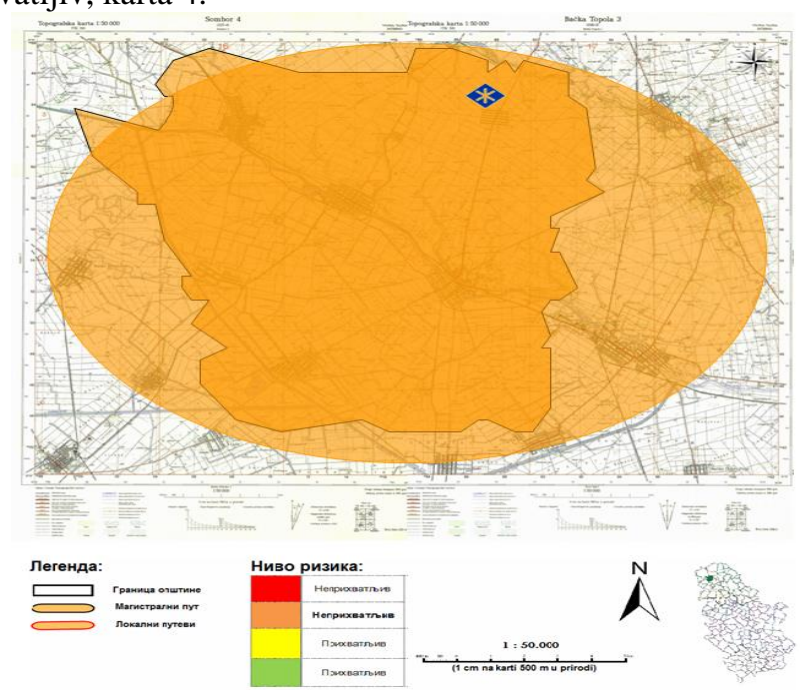

Karta rizika br.4. Snežne mećave, nanosi i poledica JKP”Radnik“" Sivac, scenario neželjeni događaj sa najtežim mogućim posledicama [6]

Tretmanom neprihvatljivih rizika, odnosno preduzimanjem raznovrsnih planskih mera, redukuje se nivo rizika na prihvatljiv nivo.

Radi smanjivanja nivoa rizika od dejstva negativnih posledica, identifikovane potencijalne opasnosti ili kombinacija opasnosti, subjekti sistema zaštite i spasavanja su dužni da preduzimaju sve mere iz oblasti preventive i reagovanja.

\section{ZAKLJUČAK}

Nivo i prihvatljivost rizika od zemljotresa i snežnih mećava, nanosa i poledice se razlikuje po scenarijima.

$\mathrm{Na}$ osnovu analize scenarija za najverovatniji neželjeni događaj i procene rizika, može se konstatovati da je rizik od zemljotresa nizak i prihvatljiv, a za snežne mećave, nanose i poledicu umeren i prihvatljiv.
S druge strane, na osnovu analize scenarija za neželjeni događaj sa najtežim posledicama i procene rizika može se konstatovati da je rizik od zemljotresa umeren, dok su snežne mećave, nanose i poledicu visok, te visok rizik zahteva tretman rizika, kao i potrebu preduzimanja radnji radi smanjenja i kontrole rizika.

\section{LITERATURA}

[1] Vejnović, D., Pejanović, Lj., Rakić, M. (2018), Zaštitna fukncija bezbednosti u vanrednim situacijama, Evropski defendologija centar za naučna, politička, ekonomska, socijalna, bezbednosna, sociološka i kriminološka istraživanja, Banja Luka, str.23

[2] Zakon o smanjenju rizika od katastrofa i upravljanju vanrednim situacijama, "Sl. glasnik RS", br. 87/2018

[3] Metodologija za izradu procene ugroženosti od elementarnih nepogoda i drugih nesreća i planova zaštite i spasavanja u vanrednim situacijama, "Službeni glasnik Republike Srbije”, br. 18/2017

[4] Ministrarstvo unutrašnjih poslova RS, Procena rizika od katastrofa u RS, Na internet stranici: http://prezentacije.mup.gov.rs/svs/HTML/licence/Proce na\%20rizika\%20od\%20katastrofa\%20u\%20RS.pdf, datum pristupa 14.09.2019.

[5] Prostorni plan opštine Kula, ,Sl. list opštine Kula”, broj 11/06

[6] Seizmički hazard Republike Srbije, Na internet stranici: http://www.seismo.gov.rs/Seizmicnost/Karte_hazarda_1. htm, datum pristupa 10.09.2019.

\section{Kratka biografija:}

Drago Zorić rođen je u Somboru 1980. god. Diplomirao je 2018. godine na Fakultetu tehničkih nauka u Novom Sadu na Departmanu za građevinarstvo i geodezija, na smeru Upravljanje rizicima od katastrofalnih događaja i požara. Zaposlen je u JKP „Radnik“ Sivac. 